\title{
CORRECTION
}

\section{Correction to: Shock Response of Polymethylmethacrylate}

\author{
Jennifer L. Jordan ${ }^{1} \cdot$ Daniel Casem ${ }^{2} \cdot$ Michael Zellner $^{2}$
}

Published online: 1 March 2019

(c) Society for Experimental Mechanics, Inc 2019

\section{Correction to: \\ Journal of Dynamic Behavior of Materials. (2016) 2:372-378 \\ https://doi.org/10.1007/s40870-016-0071-5}

Table 1 had incorrect densities for the RH and Poly samples. The correct density for RH samples is $1.1892 \pm 0.0003 \mathrm{~g} /$ $\mathrm{cm}^{3}$. The correct density for Poly samples is $1.1842 \pm$ $0.0004 \mathrm{~g} / \mathrm{cm}^{3}$. The authors thank Christopher Neel from the Air Force Research Laboratory for bringing this error to our attention.

Additionally, there is an error in Eq. (6). $1.7576 \times 10^{-2}$ should be $1.7576 \times 10^{-7}$.

The original article can be found online at https://doi.org/10.1007/ s40870-016-0071-5.

Jennifer L. Jordan

jljordan@lanl.gov

1 Los Alamos National Laboratory, Los Alamos, NM 87545, USA

2 US Army Research Laboratory, Aberdeen Proving Ground, MD 21005, USA 